\title{
Relevance of Assessment Methods for Fluid Intake
}

\author{
Joan Gandy ${ }^{a, b}$ Homero Martinez ${ }^{c, d}$ Isabelle Guelinckx ${ }^{e}$ Luis A. Moreno ${ }^{f, g}$ \\ Saptawati Bardosono $^{\text {h }}$ Jordi Salas-Salvadóg, ${ }^{\text {i }}$ Stavros A. Kavouras ${ }^{j}$ \\ ${ }^{a}$ British Dietetic Association, Birmingham, and b School of Life and Medical Services, University of Hertfordshire,

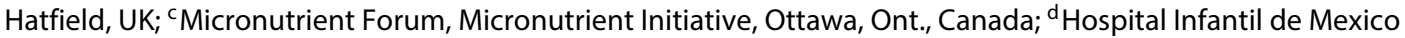

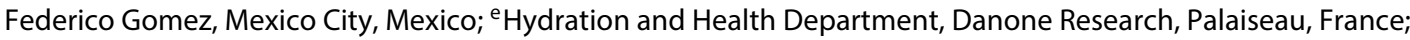 \\ ${ }^{f}$ GENUD (Growth, Exercise, NUtrition and Development) Research Group, Facultad de Ciencias de la Salud, Instituto \\ Agroalimentario de Aragón (IA2), Instituto de Investigación Sanitaria Aragón (IIS Aragón), and 9 Centro de Investigación \\ Biomédica en Red de Fisiopatología de la Obesidad y Nutrición (CIBERObn), Universidad de Zaragoza, Zaragoza, \\ Spain; ${ }^{\text {h}}$ Department of Nutrition, Faculty of Medicine, Universitas Indonesia, Jakarta, Indonesia; ${ }^{i}$ Human Nutrition \\ Unit, Hospital Universitari de Sant Joan de Reus, Faculty of Medicine and Health Sciences, IISPV (Institut d'Investigació \\ Sanitària Pere Virgili), Biochemistry Biotechnology Department, Universitat Rovira i Virgili, Reus, Spain; ${ }^{\mathrm{H} H y d r a t i o n}$ \\ Science Laboratory, Human Performance and Recreation, University of Arkansas, Fayetteville, Ark., USA
}

\section{Key Words}

Water $\cdot$ Beverages $\cdot$ Fluid intake $\cdot$ Dietary assessment methodologies $\cdot 7$-day record

\begin{abstract}
Reliable data at population level are essential to firmly establish links between fluid intake, hydration and health, investigate dose-response relationships and develop meaningful public health strategies or reference intake values. However, limited research exists regarding the most appropriate methodology for assessing beverage or total fluid intake (TFI). To date, methodologies have been developed to assess food and nutrient intake without due consideration of water or fluid intake behavior. A recent crossover study showed that a 24-hour food recall significantly underestimated mean TFI by $382 \mathrm{ml}(95 \% \mathrm{Cl} 299-465)$ compared with a fluid specific 7-day record. The authors postulated that this average difference was mainly the result of missed drinking acts between meals a 24-hour recall was used. Using a 7-day record administered in paper form or on-line has also been shown to lead to a sig-
\end{abstract}

\section{KARGER}

E-Mail karger@karger.com www.karger.com/anm

\section{(c) 2016 The Author(s) \\ Published by S. Karger AG, Basel $0250-6807 / 16 / 0686-0001 \$ 39.50 / 0$}

This article is licensed under the Creative Commons AttributionNonCommercial-NoDerivatives 4.0 International License (CC BYNC-ND) (http://www.karger.com/Services/OpenAccessLicense) Usage and distribution for commercial purposes as well as any distribution of modified material requires written permission. nificantly different mean TFI of $129 \mathrm{ml}$. Therefore, the choice of methodology might result in measurement errors that limit between-survey or between-country comparisons. Such errors may contribute to variations in estimates of TFI that cannot be explained by differences in climate, physical activity or cultural habits. A recent survey confirmed the variation in methodologies used in European national dietary surveys. Since these surveys form the basis for setting adequate intakes for total water intake, measurement error between surveys should be limited, highlighting the need for the development of a consistent methodology that is validated for water and TFI estimation.

(C) 2016 The Author(s)

Published by S. Karger AG, Basel

\section{Relevance of Assessment Methods for Fluid Intake}

With increasing interest in the links between beverage intake, hydration and health [1], it is important to develop accurate assessments of water and fluid intake at both individual and population level. Without reliable intake
Joan Gandy

British Dietetic Association and School of Life and Medical Services Charles House, 148/9 Great Charles Street Queensway Birmingham B3 3HT (UK)

E-Mail joan.gandy@btinternet.com 
data at population level, it is not possible to firmly establish these links, investigate dose-response relationships or develop meaningful public health policies or reference intake values. It is important to emphasize that data from population surveys are also used for water quality and exposure studies (e.g., disinfection by-products) [2]. Currently, there is no consensus regarding the most reliable method to assess total fluid intake (TFI, the sum of water and all other beverages) [3]; for clarity the term TFI, which does not include water from food, will be used in this article.

\section{Current Methodologies for Assessing TFI}

Until the last decade, the research into TFI, hydration and health mostly focused on acute dehydration in specific populations such as patients, athletes or those working in extreme hot environment. The interest in TFI of the general population is relatively new and as a consequence, there is limited research into the most appropriate methodology to assess TFI [4], as illustrated by a recent systematic review focused on fluid intake [5]. The methodologies used to assess intakes included single and multiple 24-hour recalls, food frequency questionnaires and/or food diaries. A 24 -hour recall was the most frequently used method ( 29 out of 65 studies, $45 \%$ ), 22 of which were single 24 -hour recalls. This inconsistency in methodology also has been shown to exist in European surveys [6]. Similarly the data consulted by the European Food Safety Authority (EFSA) to derive dietary recommendations on total water intake [7], which was taken from EFSA's Comprehensive European Food Consumption Database, also involved a variety of methodologies. There was less reliance on 24-hour recalls [8] with 7-day dietary records being used most frequently. A wide variation of TFI exists in European surveys; for example, Italian adults have been reported to drink less than half the volume consumed by adults in Germany (941 and 1,014 $\mathrm{ml} /$ day for women and men in Italy vs. 2,366 and 2,659 $\mathrm{ml} /$ day for German women and men, respectively) [6]. While these differences may be due to cultural habits, climate and physical activity, the heterogeneity of methodologies is likely a contributing factor.

Such variability in TFI data raise concerns about the validity of data used for the EFSA recommendations for adequate intake of water [7], which used data from population studies as part of TFI calculations. As a result of these concerns Gandy et al. [unpublished data] recently surveyed 21 European countries to look at current assess- ment methods of TFI in population surveys. Data from 10 countries were analyzed ( 11 responded but 1 reported collecting purchasing data not intake data and was therefore not included in the analysis). The responses showed an apparent awareness of the need to assess TFI by including specific questions on intake of water and other fluids, and coding accordingly. While the survey by Gandy et al. [unpubl. data] did not receive responses from exactly the same countries whose data were available to EFSA in 2010 to set the adequate intakes for total water intake [7], the inconsistency in the methodologies are comparable, as shown in table 1. To facilitate comparisons of nutrient intake across Europe, EFSA recommended using 24-hour recall, on 2 non-consecutive days, as the preferred methodology [9]. While 24-hour recall is relatively inexpensive and does not overburden participations, its suitability as the best method to use for TFI is debatable. However, a recent crossover study involving nearly 600 adults and adolescents showed significant differences in the estimation of TFI when a 24-hour recall was compared to a 7-day fluid-specific diary [10]. While there was a significant correlation between the 2 methods, the 24-hour recall underestimated TFI by $382 \mathrm{ml}$ (95\% CI 299-465), when compared to the 7-day diary. In addition, the underestimation increased with increasing intake, resulting in a mean underestimation of $1,265 \mathrm{ml}$ for the highest quartile of TFI. On average, the 7-day fluid-specific diary recorded the equivalent of 2 more drinking occasions. The authors hypothesised that these drinking occasions took place outside meals and were therefore less likely to be included when using a 24-hour recall. Similarly Sebastian et al. [11] reported that changes in the methodology of the WWEIA/NHANES impacted estimation of drinking water. These studies clearly demonstrate that choice of methodology may result in measurement errors that limit the interpretation of data.

All present methodologies used to assess TFI were developed to study food and nutrient intakes, without due consideration of drinking behavior, and therefore are usually structured around meals. In addition, they have most often been validated for energy, not TFI. Unlike food intake, water and other fluids are drunk throughout the day [12]; because these fluids often do not contribute to energy intake, they may not be recorded. The choice of beverage or drink may vary across the day (e.g., alcohol is more likely to be consumed in the evening [13]) and across the week (i.e., weekday vs. weekend). The amount of fluid drunk also will vary from day to day depending on factors such as physical activity, environment, climate and culture. For example, in the UK, it has been shown 
Table 1. Overview of methodologies used in European population surveys to assess fluid intake

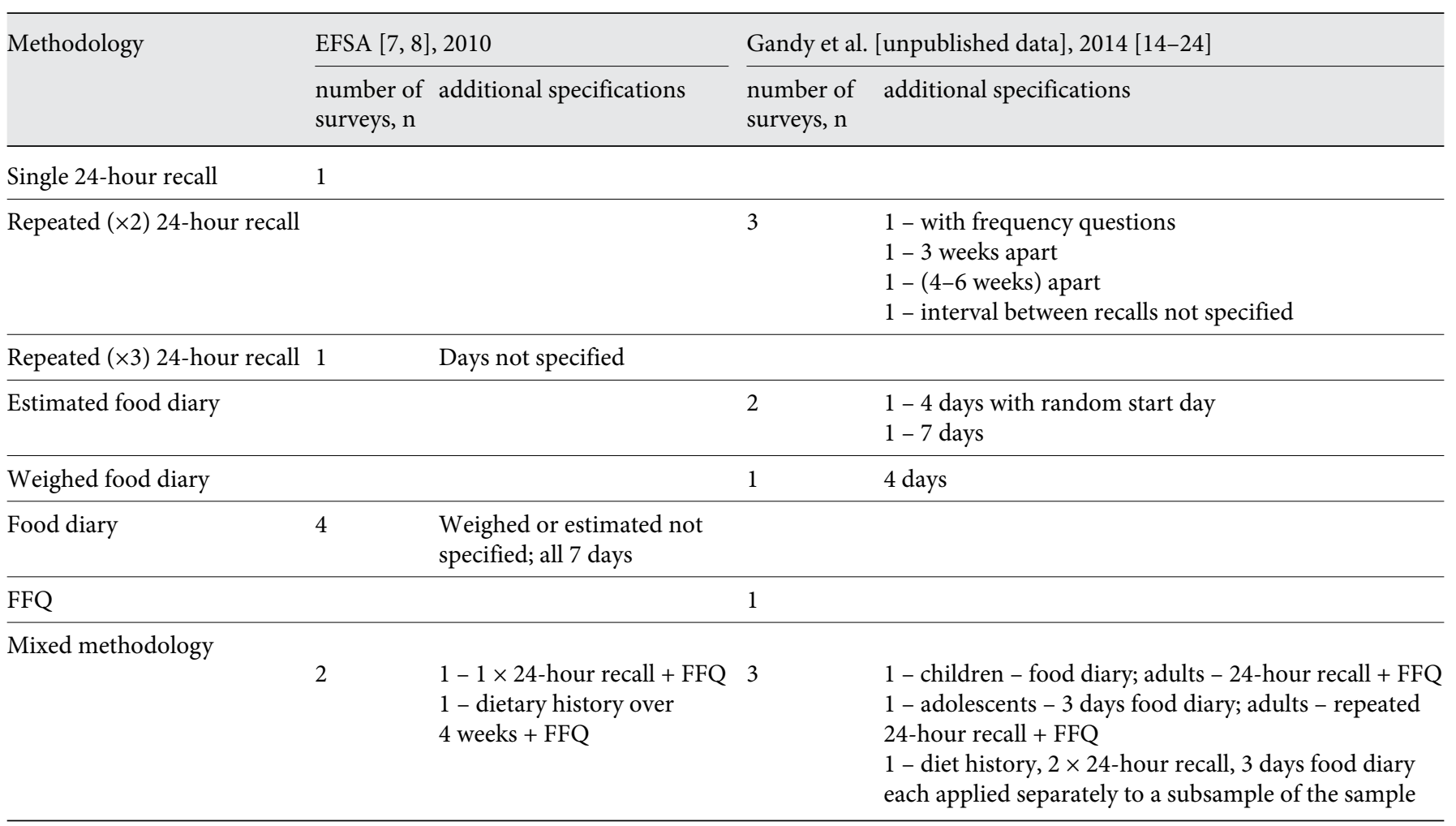

FFQ = Food frequency questionnaire

that TFI and alcoholic beverage intake was higher during weekends, especially amongst adult men [13]. Therefore, a diary or 24-hour recall structured around meals is likely to underestimate total water intake because they do not capture all drinking events.

The methodologies used to assess food and nutrition are validated against a particular nutrient. For example, UK's National Diet and Nutrition Survey is validated for energy [25]; however, to date, no published methodologies have been validated for water or TFI [3]. This was confirmed by the recent European survey by Gandy et al. [unpubl. data], described above. It is essential that a methodology be developed which captures all drinking events and is validated against a reference standard such as deuterium dilution. When accomplished, this method will reduce measurement error, facilitate interpretation of data and allow valid comparisons between population groups and countries. The Liq. $\operatorname{In}^{7}$ surveys aimed to address these limitations by consistently using a harmonized survey protocol and a 7-day fluid-specific record, in comparisons of TFI and types of beverages consumed by children, adolescents and adults across 13 countries [26-29].

Assessment of Fluid Intake

\section{Other Methodological Considerations}

While the study by Bardosono et al. [10] clearly showed that a 7-day fluid-specific diary was capable of capturing more drinking occasions, resulting in a higher estimate of TFI, it is important to consider factors that may affect participant compliance and ease of recording. As a result, there is increasing interest in the use of computerized and on-line technologies. The impact of such technologies on TFI recording has been investigated in a recent cross-over study, in which an online 7-day food record was compared with a paper version [30]. Reported water intake from fluids was significantly higher when using the online version compared with the paper version $(1,348 \pm 36$ vs. $1,219 \pm 34 \mathrm{ml} /$ day, respectively). The authors postulated that this difference occurred because the online version captured more drinking events outside of meals. Interestingly, more than $75 \%$ of the 246 participants reported that they preferred using the online version.

The survey by Gandy et al. [unpubl. data] also highlighted methodological differences across Europe including the recording of dilution factors for cordials, powders 
and concentrates. Two countries reported using standard dilution factors although only one has published these data [31]. The categorization and definition of beverage types varied amongst the countries that responded, making comparisons between countries difficult.

Training of survey staff and participants is critical to accurately recording the beverage type and quantity consumed. For example, ambiguities exist regarding how to judge intake volume (i.e., with or without standard measure cups and glasses or photographs) and whether volume drunk or the volume offered is recorded. Currently, no European survey method incorporates a marker of hydration status such as 24-hour urine osmolality [1]. Although this additional measurement would require ethical approval by a human research review board and possibly additional funding, it also would allow discovery of new insights and relationships.

\section{Conclusions}

With increasing interest in the relationship between the types of beverages consumed, hydration and health, it is essential that efforts be made to collect robust, pre- cise and valid epidemiological data. The assessment of TFI and beverage type is challenging given the lack of scientific evidence to support the use of any particular methodology. In Europe, and perhaps worldwide, a variety of methodologies are used for fluid assessment, and none has been validated for water or TFI intake Without a validated methodology or better understanding of potential measurement errors, it is difficult to develop meaningful public health initiatives or recommendations about intake. In addition, the lack of a coordinated approach to TFI assessment has, until recently with the Liq. In $^{7}$ surveys, made comparisons between populations and groups difficult if not invalid. Additional research is required to develop a consistent and valid approach to the assessment of water, beverages and TFI.

\section{Disclosure Statement}

J.G., H.M., J.S.-S., L.A.M. and S.A.K. are members of the fluid intake expert group of Danone Research. S.A.K., J.S.-S. and L.A.M. have received research grants from Danone Research. J.G. is a member of the fluid intake expert group of International Life Sciences Institute Europe. I.G. is an employee of Danone Research.

\section{References}

1 Perrier ET, Buendia-Jimenez I, Vecchio M, Armstrong LE, Tack I, Klein A: Twenty-fourhour urine osmolality as a physiological index of adequate water intake. Dis Markers 2015; 2015:231063.

2 Villanueva CM, Kogevinas $M$, Cordier S, Templeton MR, Vermeulen R, Nuckols JR, Nieuwenhuijsen MJ, Levallois P: Assessing exposure and health consequences of chemicals in drinking water: current state of knowledge and research needs. Environ Health Perspect 2014;122:213-221.

3 Gandy J: Water intake: validity of population assessment and recommendations. Eur J Nutr 2015;54(suppl 2):11-16.

4 Popkin BM, D'Anci KE, Rosenberg IH: Water, hydration, and health. Nutr Rev 2010;68: 439-458.

5 Özen AE, Bibiloni Mdel M, Pons A, Tur JA: Fluid intake from beverages across age groups: a systematic review. J Hum Nutr Diet 2015;28:417-442.

6 Nissensohn M, Castro-Quezada I, Serra-Majem L: Beverage and water intake of healthy adults in some European countries. Int J Food Sci Nutr 2013;64:801-805.

7 European Food Safety Authority (EFSA): Scientific opinion on dietary reference values for water. EFSA J 2010;8:1459.
8 Vergne S: Methodological aspects of fluid intake records and surveys. Nutr Today 2012; 47:S7-S10.

9 European Food Safety Authority: Guidance on the EU menu methodology. EFSA J 2014; 12:3944.

10 Bardosono S, Monrozier R, Permadhi I, et al: Total fluid intake assessed with a 7-day fluid record versus a 24 -h dietary recall: a crossover study in Indonesian adolescents and adults. Eur J Nutr 2015;54(suppl 2):17-25.

11 Sebastian RS, Wilkinson Enns C, Goldman JD, Moshfegh AJ: Change in methodology for collection of drinking water intake in what we eat in America/national health and nutrition examination survey: implications for analysis. Public Health Nutr 2012;15:1190-1195.

12 Le Bellego L, Jean C, Jiménez L, et al: Understanding fluid consumption patterns to improve healthy hydration. Nutr Today 2010; 45:S22-S26.

13 Gibson S, Shirreffs SM: Beverage consumption habits '24/7' among British adults: association with total water intake and energy intake. Nutr J 2013;12:9.

14 Directorate of Health, Icelandic Food and Veterinary Authority and the Unit of Nutrition Research (RIN) at the University of Iceland (2012) Нvað borða Íslendingar? http://www.landlaeknir.is/servlet/file/ store93/item14901/Hvað\%20borða\%20Íslendingar_april\%202012.pdf (accessed March 2016).

15 National Institute for Public Health and the Environment: Dutch National Food Consumption Survey. 2012. http://www.rivm.nl/ en/Topics/D/Dutch_National_Food_ Consumption_Survey (accessed March 2016).

16 Ruprich J, Dofkova M, Rehurkova I, et al: Individual food consumption - the national study SISP04. 2012. http://czvp.szu.cz/spotrebapotravin.htm (accessed April 2016).

17 Bates B, Lennox A, Prentice A, et al: National Diet and Nutrition Survey Results from Years $1,2,3$ and 4 (combined) of the Rolling Programme (2008/2009-2011/2012). London: Public Health England Publications, 2014.

18 Irish Universities Nutrition Alliance: North/ South Ireland Food Consumption Survey. 2001. http://www.iuna.net/?p=25 (accessed March 2016).

19 Amcoff E, Edberg A, Enghardt H, et al: Riksmaten - vuxna 2010-2011 Livesmedels- och naringsintage bland vuxma I Sverige. 2012. http://www.livsmedelsverket.se/globalassets/ matvanor-halsa-miljo/kostrad-matvanor/ matvaneundersokningar/riksmaten_2010_ 20111.pdf?id=3588 (accessed April 2016) 
20 Szeitz-Szabó M, Bíró L, Bíró Gy, et al: Dietary survey in Hungary, 2009. Part I. Macronutrients, alcohol, caffeine, fibre. Acta Aliment Hung 2011;40:142-152.

21 Bíró L, Szeitz-Szabó M, Bíró Gy, et al: Dietary survey in Hungary, 2009. Part II: Vitamins, macro- and microelements, food supplements and food allergy. Acta Aliment Hung 2011;40:301-312.

22 Elmadfa I: Österreichischer Ernährungsbericht. 2012. http://www.bmg.gv.at/cms/home/ attachments/4/5/3/CH1048/CMS134874979 4860/oeb12.pdf (accessed March 2015).

23 Devriese S, Huybrechts I, Moreau M, et al: De Belgische Voedselconsumptiepeiling. 2004. https://www.wiv-isp.be/epidemio/epinl/ index 5.htm (accessed March 2016).

24 Eisinger-Watzl M, Straßburg A, Ramünke J, et al: Comparison of two dietary assessment methods by food consumption: results of the German National Nutrition Survey II. Eur J Nutr 2015;54:343-354.
25 Henderson L, Gregory J, Swan G: National Diet and Nutrition Survey: Adults Aged 19 to 64 Years. Volume 1: Types and Quantities of Food Consumed. London, TSO, 2002.

26 Guelinckx I, Ferreira-Pêgo C, Moreno LA, Kavouras SA, Gandy J, Martinez H, Bardosono S, Abdollahi M, Nasseri E, Jarosz A, Ma G, Carmuega E, Babio N, Salas-Salvadó J: Intake of water and different beverages in adults across 13 countries. Eur J Nutr 2015;54(suppl 2):45-55.

27 Guelinckx I, Iglesia I, Bottin JH, De MiguelEtayo P, González-Gil EM, Salas-Salvadó J, Kavouras SA, Gandy J, Martinez H, Bardosono S, Abdollahi M, Nasseri E, Jarosz A, Ma G, Carmuega E, Thiébaut I, Moreno LA: Intake of water and beverages of children and adolescents in 13 countries. Eur J Nutr 2015; 54(suppl 2):69-79.

28 Ferreira-Pêgo C, Guelinckx I, Moreno LA, Kavouras SA, Gandy J, Martinez H, Bardosono S, Abdollahi M, Nasseri E, Jarosz A, Babio N, Salas-Salvadó J: Total fluid intake and its determinants: cross-sectional surveys among adults in 13 countries worldwide. Eur J Nutr 2015;54(suppl 2):35-43.

29 Iglesia I, Guelinckx I, De Miguel-Etayo PM, González-Gil EM, Salas-Salvadó J, Kavouras SA, Gandy J, Martínez H, Bardosono S, Abdollahi M, Nasseri E, Jarosz A, Ma G, Carmuega E, Thiébaut I, Moreno LA: Total fluid intake of children and adolescents: crosssectional surveys in 13 countries worldwide. Eur J Nutr 2015;54(suppl 2):57-67.

30 Monnerie B, Tavoularis LG, Guelinckx I, Hebel P, Boisvieux T, Cousin A, Le Bellego L: A cross-over study comparing an online versus a paper 7-day food record: focus on total water intake data and participant's perception of the records. Eur J Nutr 2015;54(suppl 2): 27-34.

$31 \mathrm{Ng}$ SW, Ni Mhurchu C, Jebb SA, et al: Patterns and trends of beverage consumption among children and adults in Great Britain, 1986-2009. Br J Nutr 2012;108:536-551. 